\title{
Water Content Influence on Properties of Red-Layers in Guangzhou Metro Line, China
}

\author{
Jifeng Liu and Huizhi Zhang \\ Department of Architecture and Civil Engineering, Sanming University, Fujian, China \\ Correspondence should be addressed to Jifeng Liu; ph_dliujifeng@126.com
}

Received 14 November 2016; Revised 9 March 2017; Accepted 12 March 2017; Published 4 May 2017

Academic Editor: Fernando Lusquiños

Copyright ( 2017 Jifeng Liu and Huizhi Zhang. This is an open access article distributed under the Creative Commons Attribution License, which permits unrestricted use, distribution, and reproduction in any medium, provided the original work is properly cited.

In order to reveal water content influence on shear strength, swelling, and creep properties of red-layers in Guangzhou Metro, Southern China, the typical red-layers rock and soil specimens were experimentally studied by direct shear test, UU triaxial test, swelling test, and creep test, and the measured data were analyzed. The results showed that soil internal friction angle exponentially decreased with the water content increase and cohesion in accordance with the Gaussian function firstly increased and then decreased with the increase of water content. Expansion rate significantly decreased with the initial water content increase. The red sandstone had very strong isotropic expansion and disintegration properties. The mechanism of water content effect on red-layers properties was water induced microstructures and mineral compositions change which caused the macro physical and mechanical characteristics degradation. The results should provide the reference for further research for water induced damage mechanism or creep damage control of red-layers in engineering practice.

\section{Introduction}

In the southeast of China, there are widely distributed redlayers, for example, in Guangzhou city, Guangdong province. The red-layers are rich in minerals such as expansive clay minerals, soluble minerals, and organic minerals, which lead the special engineering geological properties of redlayers in comparison with common clay; for example, the expansion and strong viscosity properties, caused by engineering construction disturbance and water intrusion induced microstructures damage or/and mineral compositions change of red-layers, are the special features of redlayers which are responsible for many engineering problems; for instance, when Guangzhou Metro Lines were excavated in the red-layer grounds by shield tunnel, the expansion and strong viscosity properties of red-layers could lead to the large squeezed muck wear formation ahead of shield cutters, which would further lead to the cutter torque decrease, the thrust sharply increase, and the excavation speed significantly decrease; once the shield screw conveyor was failure to dump the squeezed muck in time, the increase of the shield face pressure would lead to severe spewing collapse. Such accidents have occurred three times in the Guangzhou Metro No. 2 Line tunnel construction under the Pearl River [1-6].

The physical and mechanical properties of red-layers, including the mudstone, argillaceous silty sand rock, silty sand, and fully or strongly weathered granite, are largely affected by water content. In general, the red-layers have the favorable engineering properties in natural state, but the water content change and construction disturbance could lead to significant difference in the strength and deformability of red-layers, which would present serious security and stability problems for those regions of engineering construction especially for Guangzhou Metro Line construction $[1,2]$.

The physical and mechanical properties of red-layers with different water contents have been widely studied. Zhang et al. [7] proposed and verified an X-ray computed tomography (CT) method to measure the water content of red clay cylinders. Deng et al. [8] reported that the creep fracture strength and long-term strength of red-layer soft rock degraded significantly during the water-rock interaction process, and the specimen microstructure changed its state 
TABLE 1: Main test items.

\begin{tabular}{|c|c|c|c|c|c|c|}
\hline Test method & $\begin{array}{l}\text { Specimen } \\
\text { type }\end{array}$ & Sampling site & Sampling depth & Test groups & $\begin{array}{l}\text { Number of } \\
\text { specimens }\end{array}$ & $\begin{array}{c}\text { Lithology } \\
\text { description }\end{array}$ \\
\hline Fast shear test & $\begin{array}{l}\text { Remolded } \\
\text { soil }\end{array}$ & $\begin{array}{c}\text { Zhujiang New Town } \\
\text { Station }\end{array}$ & $12 \mathrm{~m} \sim 17 \mathrm{~m}$ & 8 & 32 & Red clay \\
\hline Triaxial test & $\begin{array}{c}\text { Remolded } \\
\text { soil }\end{array}$ & $\begin{array}{c}\text { Zhujiang New Town } \\
\text { Station }\end{array}$ & $12 \mathrm{~m} \sim 17 \mathrm{~m}$ & 10 & 30 & Red clay \\
\hline Expansion test & $\begin{array}{c}\text { Undisturbed } \\
\text { and disturbed } \\
\text { rock }\end{array}$ & Wushan Road Station & $12 \mathrm{~m}$ & 1 & 5 & $\begin{array}{c}\text { Red } \\
\text { sandstone }\end{array}$ \\
\hline Creep test & $\begin{array}{l}\text { Undisturbed } \\
\text { rock }\end{array}$ & $\begin{array}{l}\text { Zhujiang New Town } \\
\text { Station }\end{array}$ & $17.8 \mathrm{~m} \sim 20 \mathrm{~m}$ & 1 & 10 & $\begin{array}{c}\text { Red } \\
\text { sandstone }\end{array}$ \\
\hline
\end{tabular}

from dense to loose and porous. Ma et al. [9] showed that Yunnan red clay failure envelope was affected by its saturation degree. Geng et al. [10] studied the influence of water content and clay content on the shear strength of unsaturated red clay. Hu et al. [11] investigated the effect of water content on the stable swelling capacities, swelling process, and characteristics of red bed mudstone. Bi et al. [12] conducted directly shear tests to investigate the effect of water content on the shearing strength of red clay.

However, limited studies have been conducted on the mechanism of water content influence on the red-layers properties. In most studies, only water content influence on the physical or mechanical features of red-layers specimens was considered, but the mineral compositions and microstructures change was ignored; some studies have showed that the water inside the samples did effect the mineral compositions and microstructures of red-layer soft rock, which yielded macroscopic degradation of mechanical parameters (Liu et al. $2009 ;[8]$ ), so the physical and mechanical behaviors of redlayers with different water contents have not yet been fully investigated. Therefore, more information about the water content influence on the physical and mechanical properties of red-layers should be obtained.

In this paper, a series of experimental tests were conducted on red-layers specimens with different water contents. The specific details of experimental tests were listed as follows.

(1) The specimens of different typical red-layers, including red clay, moderately weathered red clay, moderately to strongly weathered red clay, sandstone, red sandstone, weathered granite, and shield tunnel excavated soil, with intact or reconstituted state, were described and prepared.

(2) Static tests were carried out on typical red-layers rock and soil specimens with different water contents by direct shear test, UU triaxial test, and unconfined swelling test to determine its mechanical properties, and the measured data were analyzed.

(3) The X-ray diffraction (XRD) was used to determine the mineral compositions and the scanning electron microscope (SEM) was adopted to explore the microstructures of typical red-layers rock and soil specimens, respectively. And the collected photos were analyzed to reveal the mechanism of water content influence on the red-layers properties.

\section{Specimens Description and Preparation}

The typical red-layers specimens were sampled at Tiyu West Road Station, Zhujiang New Town Station, Wushan Road Station, Kecun Road Station, and Tianhe Road Station of Guangzhou Metro Line, separately. The details of specimens were shown in Table 1. The sampled depth of red-layers specimens were from $8.2 \mathrm{~m}$ to $31.3 \mathrm{~m}$. The specimens consisted of 102 groups with intact and disturbed soil or rock samples, which had different shapes, such as lumpy soil, cylindrical soil, drilling core rock, and shield tunnel excavated soil. The lithologies of the samples were red clay, moderately weathered red clay, moderately to strongly weathered red clay, sandstone, red sandstone, weathered granite, and shield tunnel excavated soil, respectively (Figure 1).

The "geotechnical engineering test method standard," recommended by Ministry of Water Resources of People's Republic of China, and the "geotechnical engineering technical manual," recommended by Geotechnical Department of Nanjing Hydraulic Research Institute, were adopted as reference for specimen preparation and experiments.

For direct shear test, the preparation of red-layers specimens is as follows: firstly, the field sampled specimens were completely air-dried and then sieved by $2 \mathrm{~mm}$ sieve, and water was added to make remolded soil samples with different water contents. A total of 32 samples, with four specimens as a group, were tested. The shield tunnel excavated soil had high initial water content, that is, $w=47.236 \%$, which made the specimens hard to be directly tested; therefore, the samples were air-dried as $w=25.879 \%$ to make specimens and to be tested.

The automatic triaxial test specimens were made with different water contents by the reconstituted Zhujiang New Town Metro Station red-layers, and the UnconsolidatedUndrained (UU) triaxial test was adopted. The specimens were remolded as a cylinder with $39.1 \mathrm{~mm}$ in diameter and $80 \mathrm{~mm}$ in height with different water contents (Figure 2).

The typical red sandstone of Wushan Road Metro Station was used for unconfined swelling test. The red sandstone specimens were completely air-dried in natural condition and then were remolded into cylinder with $61.8 \mathrm{~mm}$ in diameter and $130 \mathrm{~mm}$ in height. Three transverse and three vertical direction strain gauges were glued on the cylinder 

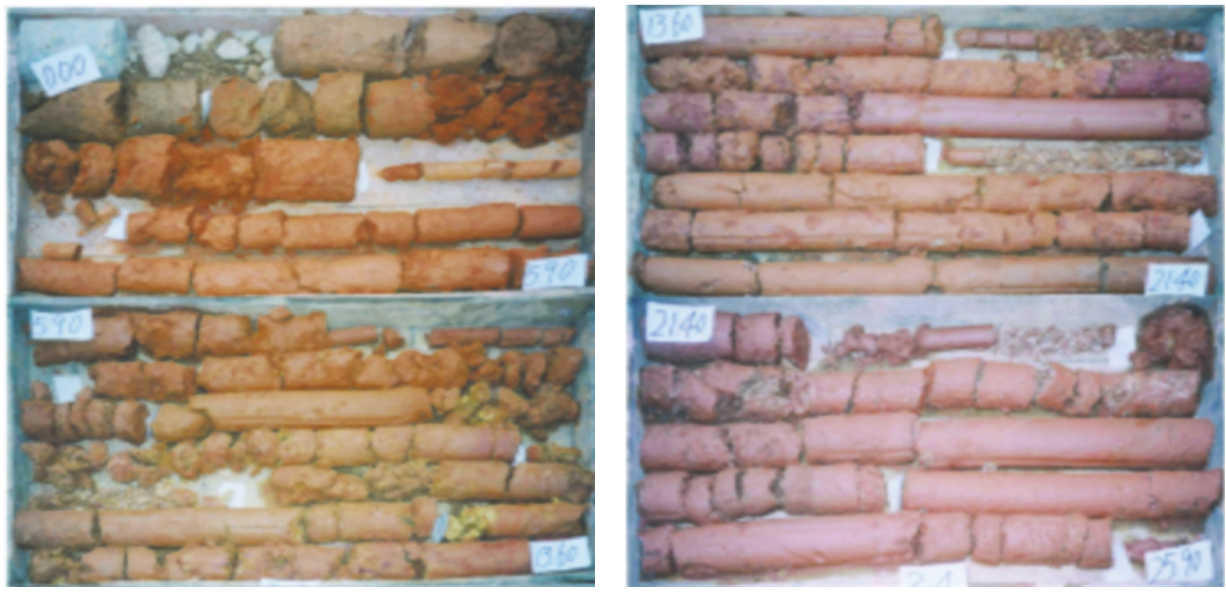

FIgURE 1: Typical borehole rock or soil cores.

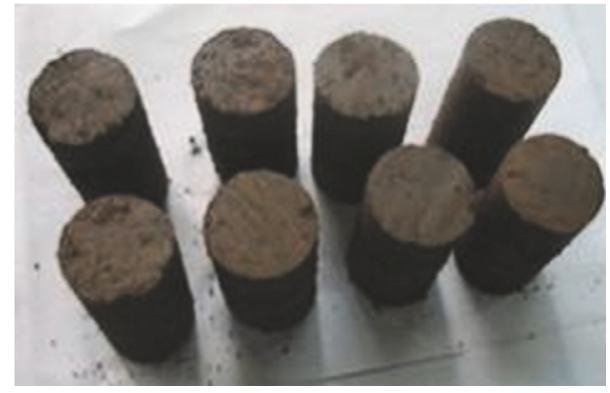

FIgURe 2: Part reconstituted soil specimens for automatic triaxial shear test.

surface with 120-degree intervals; the layout of strain gauges was shown in Figure 3. The cylinder was wrapped by thin impermeable membrane after the glue was air-dried. To ensure the uniformity of the swelling, the upper surface was slowly injected with distilled water, while the lower surface was also immersed in distilled water prior to the experiment.

Typical red sandstone specimens with dry and saturated state of Zhujiang New Town Metro Station were chosen for creep test, and the specimens' sampled depths were $17.8 \mathrm{~m} \sim 20.0 \mathrm{~m}$ (Figure 4). The samples were processed into a cylinder with $61.8 \mathrm{~mm}$ in diameter and $130 \mathrm{~mm}$ in height.

\section{Methodology}

The STGD-3 type photoelectric liquid-plastic limit tester was used to measure the water content of reconstituted soil specimen (Figure 5); the ZJ type direct shear apparatus was chosen to test the cohesion $c$ and internal friction angle $\phi$ of different water content soil specimens (Figure 6).

The KTG automatic triaxial test apparatus was used for shear strength test (Figure 7). Three specimens in each group settled the same confining pressure; that is, $P 1, P 2$, and $P 3$ were $100 \mathrm{kPa}, 200 \mathrm{kPa}$, and $400 \mathrm{kPa}$, respectively, to be tested.

The unconfined swelling test was adopted for Wushan Road Metro Station typical red sandstone. And the creep testing program was as follows: after the red sandstone specimens were prepared and data acquisition instrument and its supporting software relevant parameters were set up and checked, a red sandstone specimen was placed on the bearing platform, the load sensor was putted on the specimen upper surface, and the oil pressure was slowly increased to ensure the lower surface of oil pump closely contact to the load sensor; then the classification incremental loading creep test could be started. The test results were automatically collected by data acquisition instrument. The three levels of loading were $8 \mathrm{MPa}, 16 \mathrm{MPa}$, and $24 \mathrm{MPa}$, and each level loading duration was $144 \mathrm{~h}$ and the cumulative loading time was 18 days for one sample experiment.

For further discussion of water-weakening red-layers mechanism [13], the mineral compositions and microstructures of the red-layers specimens were tested and analyzed, according to "X-ray diffraction analysis method of the relative content of clay minerals in sedimentary rock" and "X-ray diffraction quantitative analysis method of the clay mineral aggregate and common nonclay minerals in sedimentary rocks" (The People's Republic of China Oil and Gas Industry Standard, 1995). The LEO-435VP scanning electron microscope, FEI Quanta200 field emission scanning electron microscope, and D/MAX-2500 X diffraction instrument were chosen for experiments. For the clay mineral X-ray diffraction test, each soil sample has three-piece directional diffraction and three diffraction patterns, named natural directional sheet $(\mathrm{N})$, ethylene glycol $(\mathrm{NG})$, and saturated tablet $550^{\circ} \mathrm{C}\left(550^{\circ} \mathrm{C}\right)$ (Yu et al. 2011; [13]; Zhao et al. 1990).

\section{Experimental Results and Discussion}

4.1. Direct Shear Test Results. The shear strength envelopes of the remolded soil specimens were shown in Figure 8; the values of cohesion $c$ and internal friction angle $\phi$ of the soil specimens with different water contents were shown in Table 2. The following two points can be noticed from Figure 8 and Table 2.

(1) Internal friction angle $\phi$ decreased with the increase of water content $w$; the exponential decay function could be 


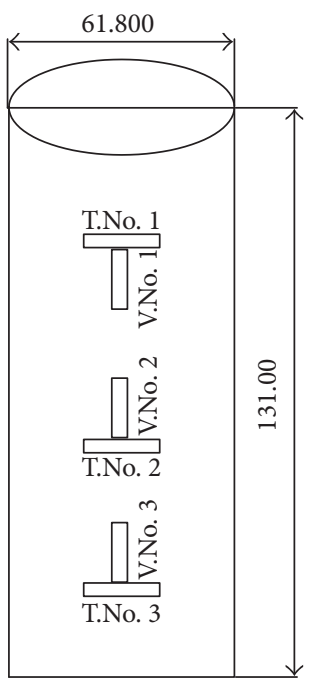

(a) Front view of strain gauges layout

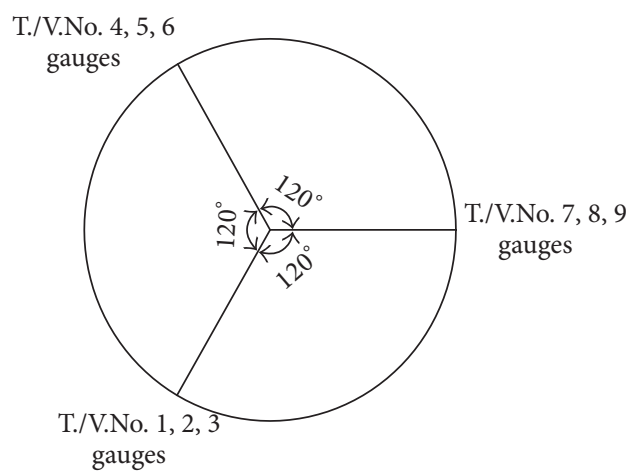

(b) Top view of strain gauges layout

FIGURE 3: Strain gauges layout on red sandstone swelling specimen (T.No.: Transverse Number; V.No.: Vertical Number).

TABLE 2: Direct shear test results with different water contents.

\begin{tabular}{lcccccccc}
\hline Contents & Group 1 & Group 2 & Group 3 & Group 4 & Group 5 & Group 6 & Group 7 & Group 8 \\
Water content (\%) & 9.99 & 13.16 & 16.92 & 17.27 & 18.348 & 20.308 & 28.226 & 37.551 \\
Internal friction angle $\left(^{\circ}\right)$ & 40.987 & 39.328 & 25.561 & 24.6447 & 23.623 & 10.238 & 1.946 & 1.356 \\
Cohesion $(\mathrm{kPa})$ & 17.19 & 14.249 & 30.78 & 30.472 & 32.113 & 45.458 & 12.573 & 8.235 \\
\hline
\end{tabular}

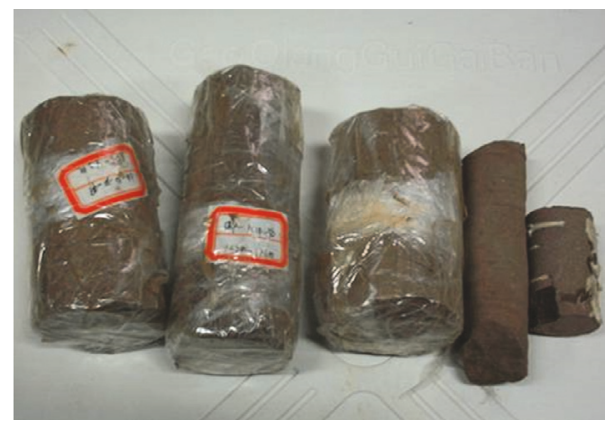

FIGURE 4: Part specimens of creep test.

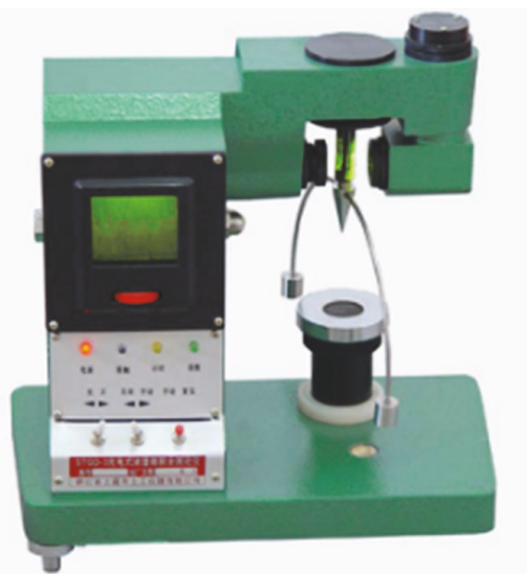

FIGURE 5: STGD-3 type photoelectric liquid-plastic limit tester.

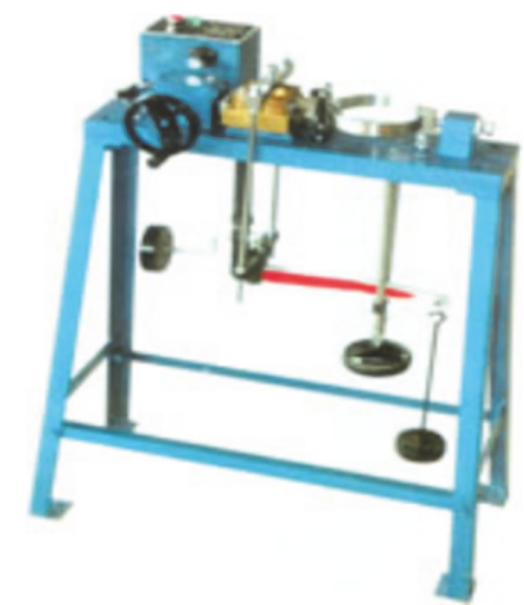

FIGURE 6: ZJ type direct shear apparatus.

chosen to present the relationship of internal friction angle $\phi$ and water content $w$. The fitting curve of internal friction angle $\phi$ and water contents $w$ was shown in Figure 9, and the fitting equation was presented as (1).

(2) Cohesion $c$ increased with the increase of water content $w$ when $w$ was less than $21.938 \%$ and decreased with the increase of water content $w$ when $w$ was higher than $21.938 \%$; that is, the inflection point occurred at $w=21.938 \%$. The Gaussian function could be chosen to fit the results. The 


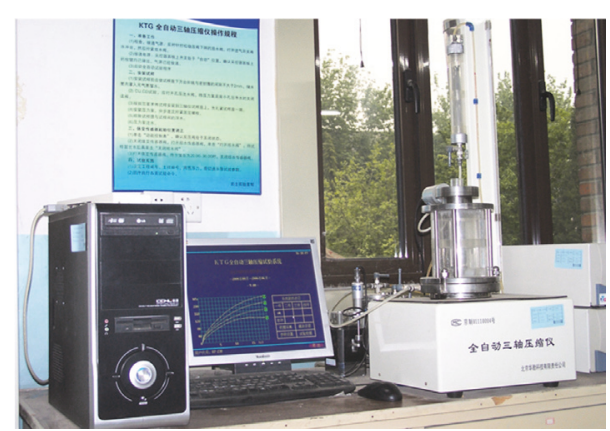

FIGURE 7: KTG automatic triaxial shear test apparatus.

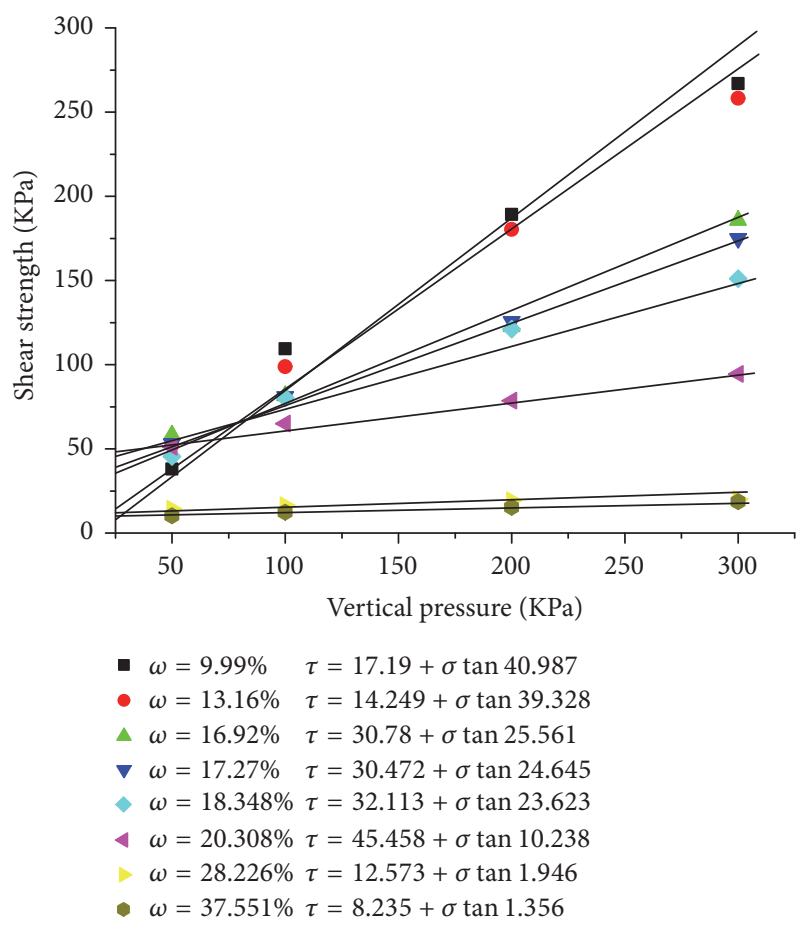

FIGURE 8: Shear strength and vertical load relationship curves.

fitting curve of cohesion $c$ and water contents $w$ was shown in Figure 10, and the curve expression was shown as

$$
\begin{aligned}
& \phi=142.157 e^{-w / 9.197} \\
& c=7.834+\frac{424.715}{8.509 \times \sqrt{\pi / 2}} e^{-2(w-21.938)^{2} / 8.509^{2}} .
\end{aligned}
$$

After careful investigation of Figures 9 and 10, one can understand that the experimental data are well in accordance with the corresponding equation curve. It was illustrated that the water content was one of the important parameters which strongly affected the shear strength of typical Guangzhou Metro red-layers; therefore, the water-weakening mechanism of the red-layers should be further studied for the safety and efficiency of Guangzhou Metro Line construction. The shear strength and water contents relationship of the red-layers established by direct shear test could provide reference for

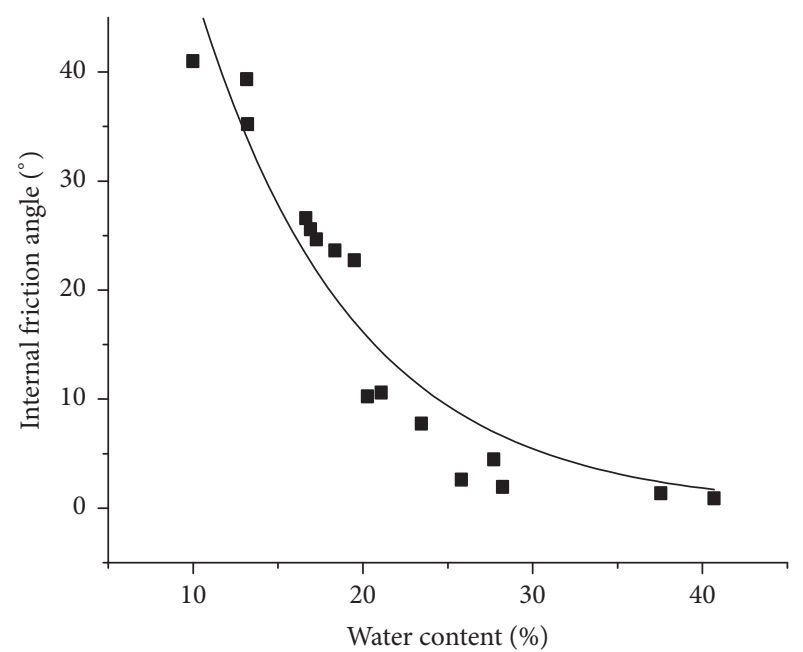

FIGURE 9: Fitting curve of water content and internal friction angle.

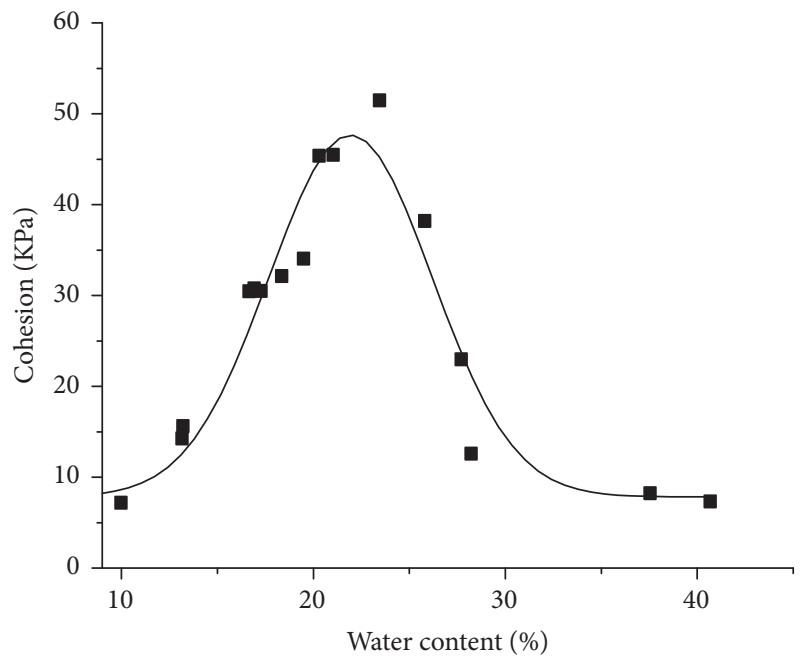

FIGURE 10: Fitting curve of water content and cohesion.

practical engineering in Guangzhou Metro Line construction.

4.2. Triaxial Test (UU) Results. The main stress difference and the axial strain curves and other valuable results were obtained after the test, as shown in Figures 11-17. The water contents and cohesion values were presented in Table 3.

(1) Cohesion $c$ increased with the increase of water content $w$ when the water content was no more than $18.5 \%$ and showed the similar variation trend with the direct shear test results.

(2) With the same confining pressure, the specimens with different water contents had different peak strength and axial deformation. In general, the peak strength increased with the increase of water content. When the water content was no more than $18.5 \%$, the peak strength firstly increased and then decreased with increase of the $\left(\sigma_{1}-\sigma_{3}\right)$ while $P 1=100 \mathrm{kPa}$ but simply increased with the increase of the $\left(\sigma_{1}-\sigma_{3}\right)$ while confining pressures $P 2=200 \mathrm{kPa}$ and $P 3=400 \mathrm{kPa}$. 
TABLE 3: Triaxial test data with different water contents.

\begin{tabular}{|c|c|c|c|c|c|}
\hline Contents & Group 1 & Group 2 & Group 3 & Group 4 & Group 5 \\
\hline Water content (\%) & 13.61 & 14.04 & 15.0 & 15.81 & 18.5 \\
\hline Max. $\sigma_{1}-\sigma_{3}, P 1=100 \mathrm{kPa}(\mathrm{kPa})$ & 99.3 & 116.2 & 111.6 & 95.7 & 202.3 \\
\hline Max. $\sigma_{1}-\sigma_{3}, P 2=200 \mathrm{kPa}(\mathrm{kPa})$ & 63.1 & 67.5 & 99.2 & 184.3 & 199.4 \\
\hline Max. $\sigma_{1}-\sigma_{3}, P 1=400 \mathrm{kPa}(\mathrm{kPa})$ & 81.2 & 96.4 & 112.1 & 156.3 & 240.4 \\
\hline Cohesion $(\mathrm{kPa})$ & 24 & 39 & 48 & 62 & 88 \\
\hline
\end{tabular}

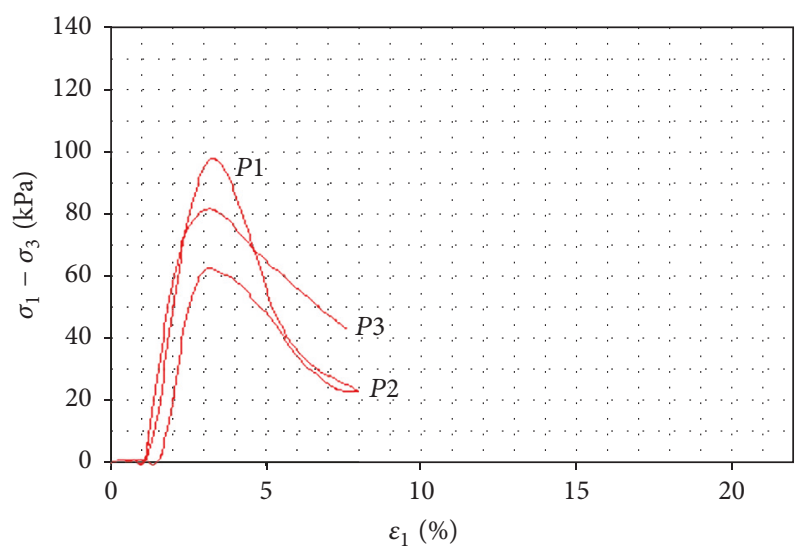

FIGURE 11: Principal stress difference and axial strain with $13.61 \%$ water content.

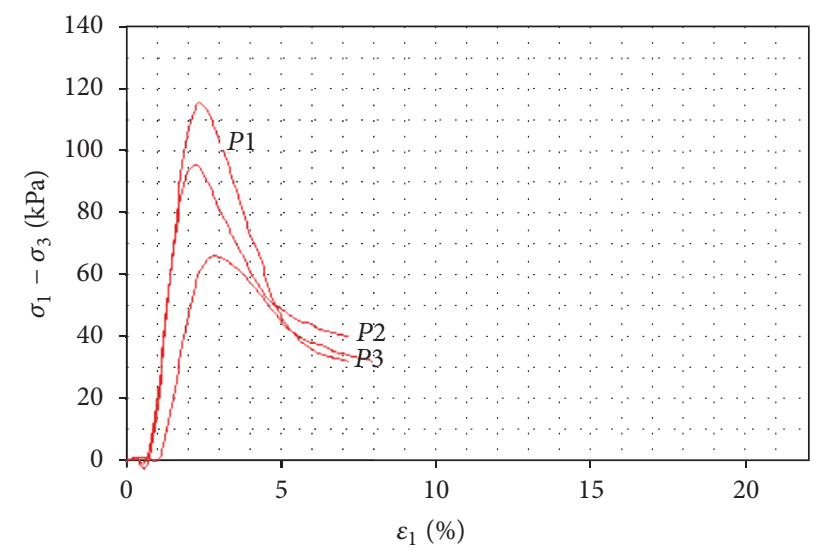

FIGURE 12: Principal stress difference and axial strain with $14.04 \%$ water content.

(3) Generally, the strain slightly decreased and then sharply increased with increase of water content; the inflection point occurred at $w=15 \%$.

(4) When the water content was $18.5 \%$, the peak strength reached the maximum value under different confining pressure, and the stain was $1 \% \sim 1.5 \%$, which was more than that of $0.2 \%-0.56 \%$, when water content was less than $18.5 \%$.

4.3. Swelling Test Results. The intact and disturbed typical red sandstone specimens of Wushan Road Metro Station were used for unconfined swelling test. After being immersed in water, the air-drying red sandstone specimen rapidly expanded with numerous cracks occurring and debris falling,

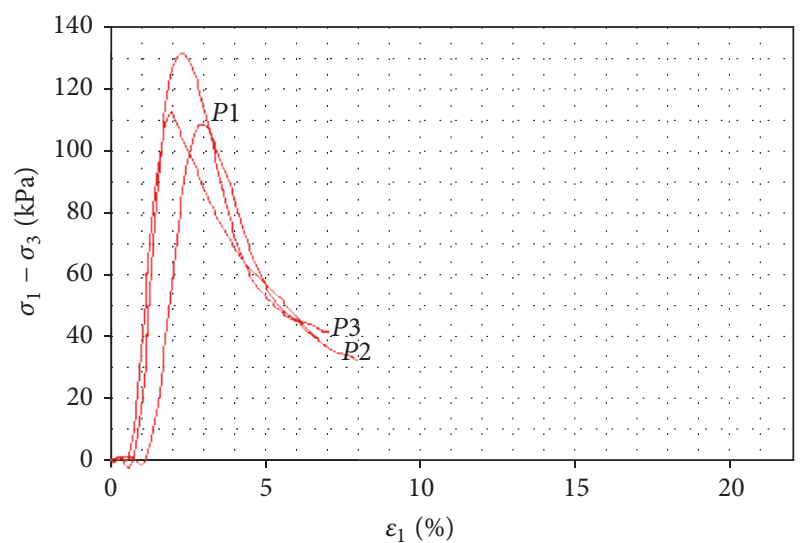

FIGURE 13: Principal stress difference and axial strain with $15.00 \%$ water content.

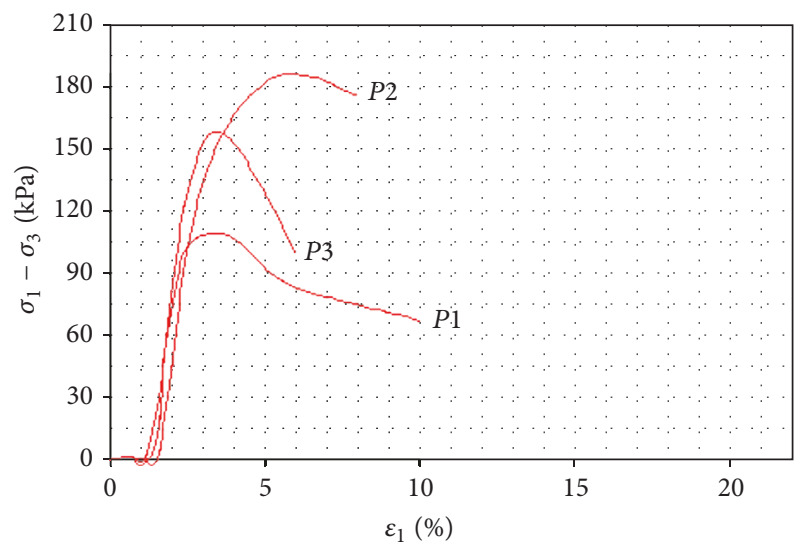

FIGURE 14: Principal stress difference and axial strain with $15.81 \%$ water content.

which indicated that red sandstone had strong swelling and disintegration potential. The swelling damage mode of red sandstone specimen was shown in Figure 18, the test results were shown in Figure 19, and the time-strain curves were shown in Figures 20 and 21. The following valuable points could be made from Figures 18-21.

(1) Water contents had the strong influence on the expansion of the disturbed specimens; generally, the expansion decreased with increase of water content, which illustrated that the water may weaken the mineral compositions or microstructures to reduce the sample expansion.

(2) There was very different swelling between the different water content samples. The smallest expansion of the highest 


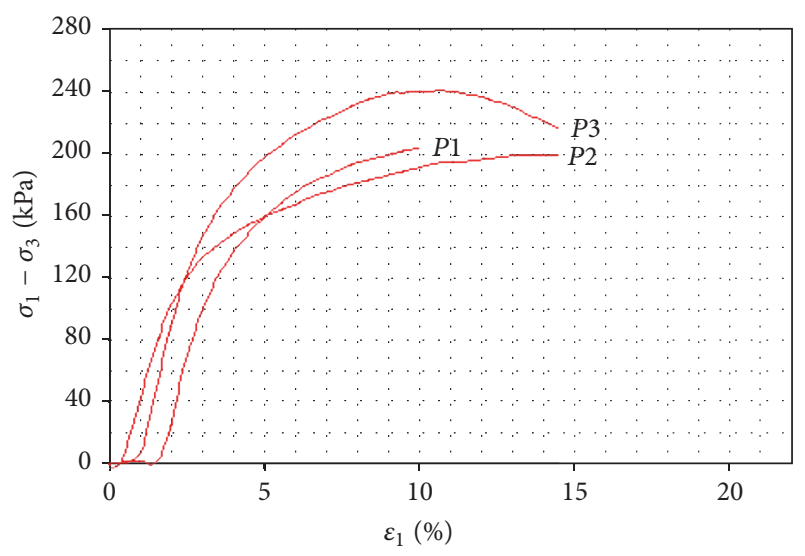

FIGURE 15: Principal stress difference and axial strain with $18.5 \%$ water content.

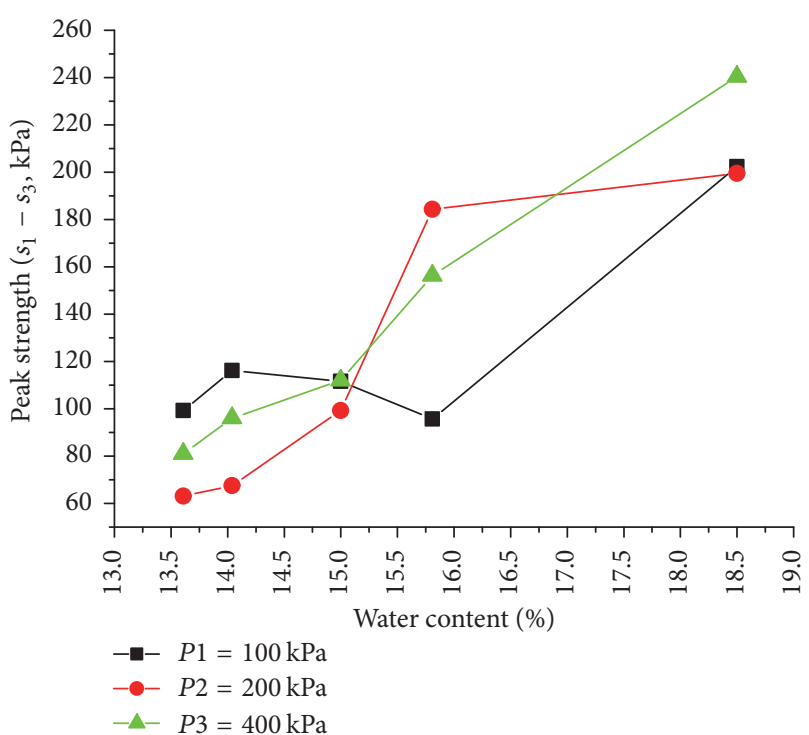

FIGURE 16: Relationship of water content and peak strength.

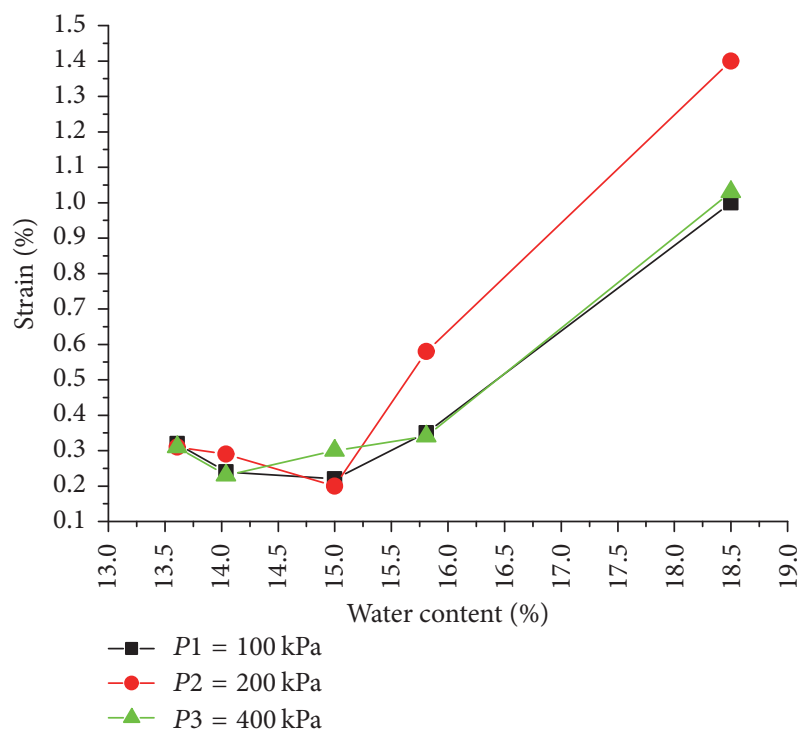

FIGURE 17: Relationship of water content and strain.

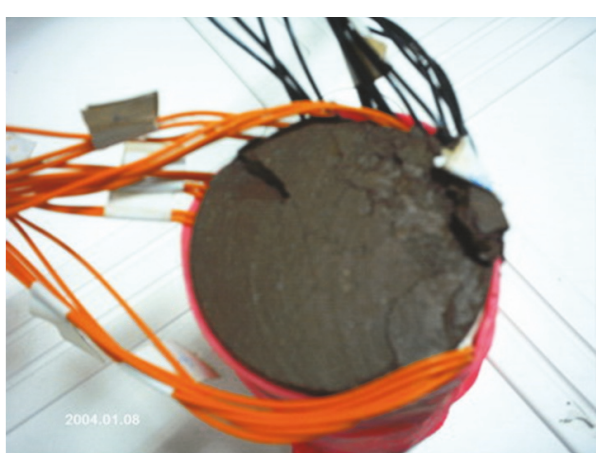

FIGURE 18: Typical specimen upper face after 10 minutes in water.

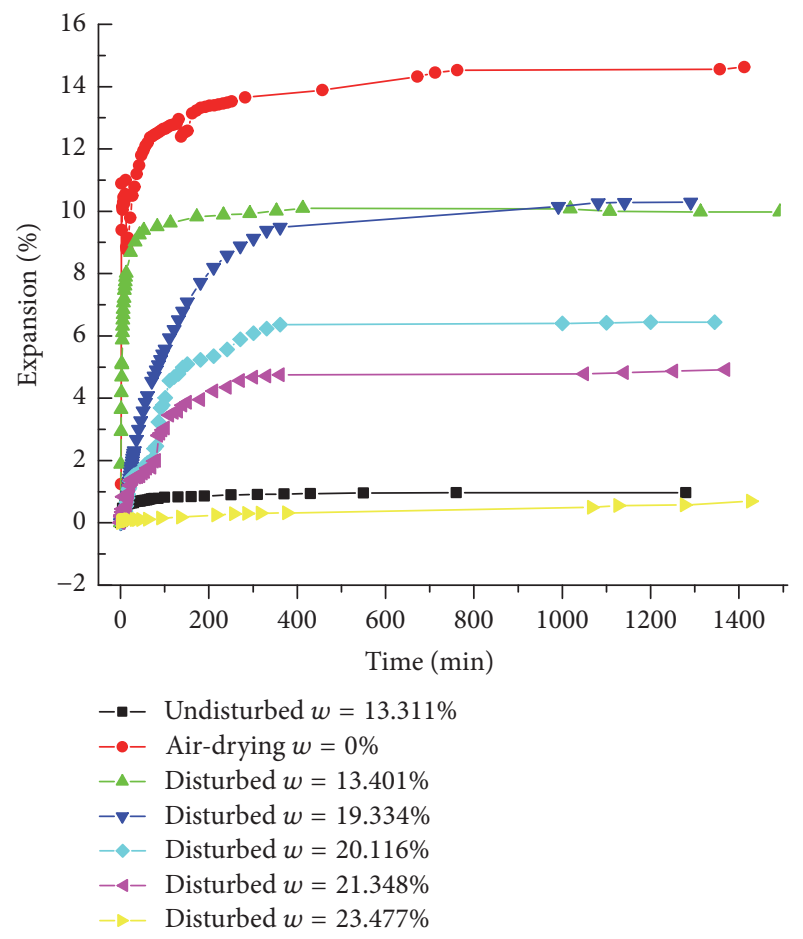

FIGURE 19: Swelling rate versus time curves of red-layers specimens.

water content sample was about $0.65 \%$, while the biggest swelling of the air-drying samples was about $14.3 \%$; the expansion has very big difference between the two specimen.

(3) The microstructures had big influence on the expansion, too. With the similar water content, that is, $13.311 \%$ of intact sample and $13.401 \%$ of disturbed specimen, the expansion was about $1 \%$ and $9.8 \%$, respectively, almost ten times difference in swelling with different microstructures.

(4) In general, there were similar vertical stains in different parts of samples, and comparatively, there were different transverse strains in different parts of samples. The lower part of sample had bigger transverse strain, that is, about $2.75 \mathrm{~mm}$, while the upper and middle part of specimen had smaller strain, that is, about $2.15 \mathrm{~mm}$ and $1.75 \mathrm{~mm}$, respectively.

4.4. Creep Test Results. The creep tests of typical dry and saturated Zhujiang New Town Metro Station red sandstone 


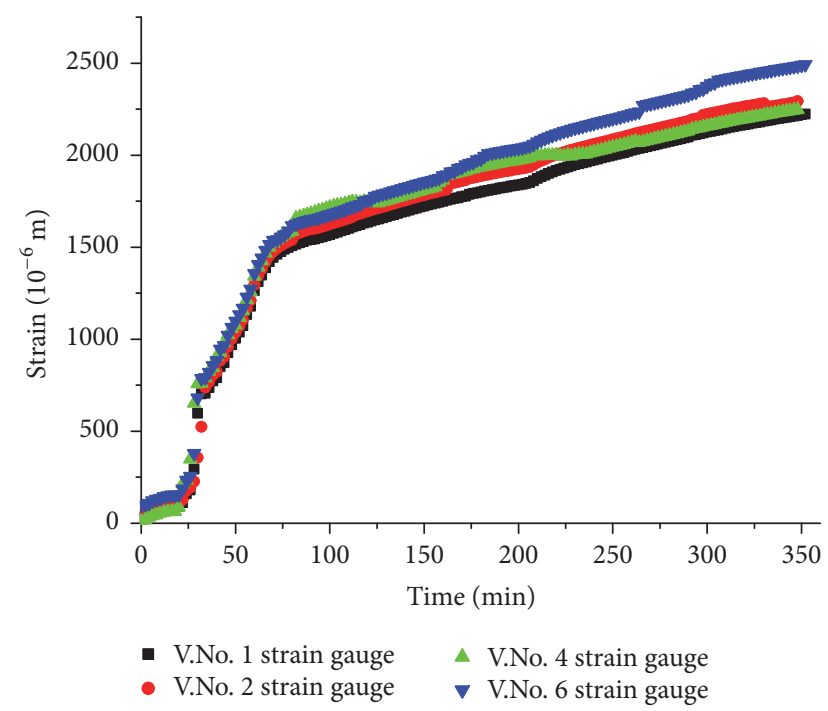

FIGURE 20: Vertical strain and time curves of No. 3 specimen.

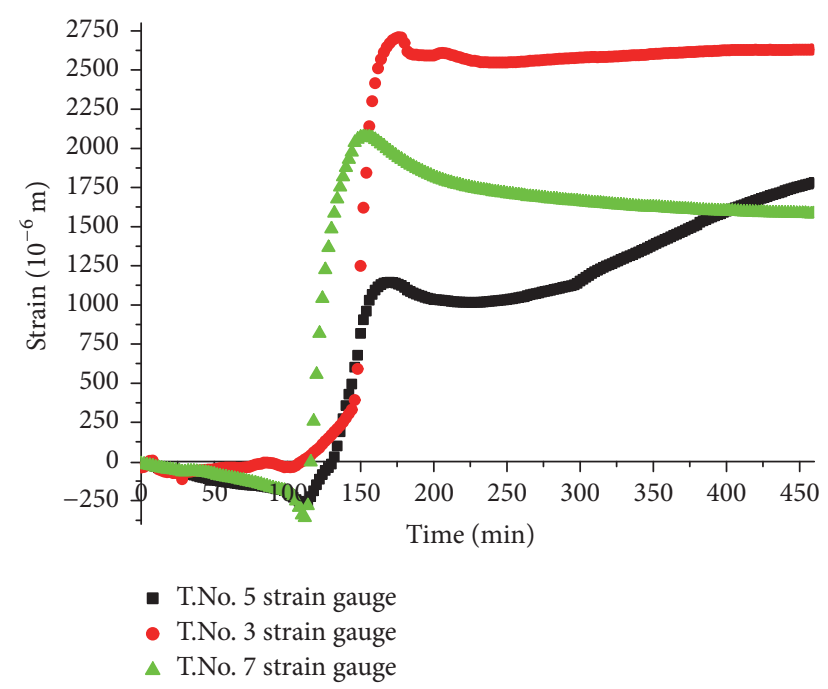

FIgURE 21: Transverse strain and time curves of No. 3 specimen.

were conducted using equipment under uniaxial compression. Based on the tested results as shown in Figure 22, the influence of water content on the creep strain could be presented as follows.

(1) All of the time-strain curves exhibited three typical stages, that is, accelerated, dumped, and steady-state stages. The deformation at accelerated stage was significant. Generally, the accelerated stage spent short period of time. In contrast, the dumped and steady-state states took long period of time.

(2) The strain of different deformation stages all increased with the increase of the loading stress; that is, the higher the loading stress, the higher the strain of different deformation stages.

(3) Water content has very significant effect on the creep properties of red sandstone; in the same loading level, the strain of air-drying samples was only 40.1 to 49.3 percent of

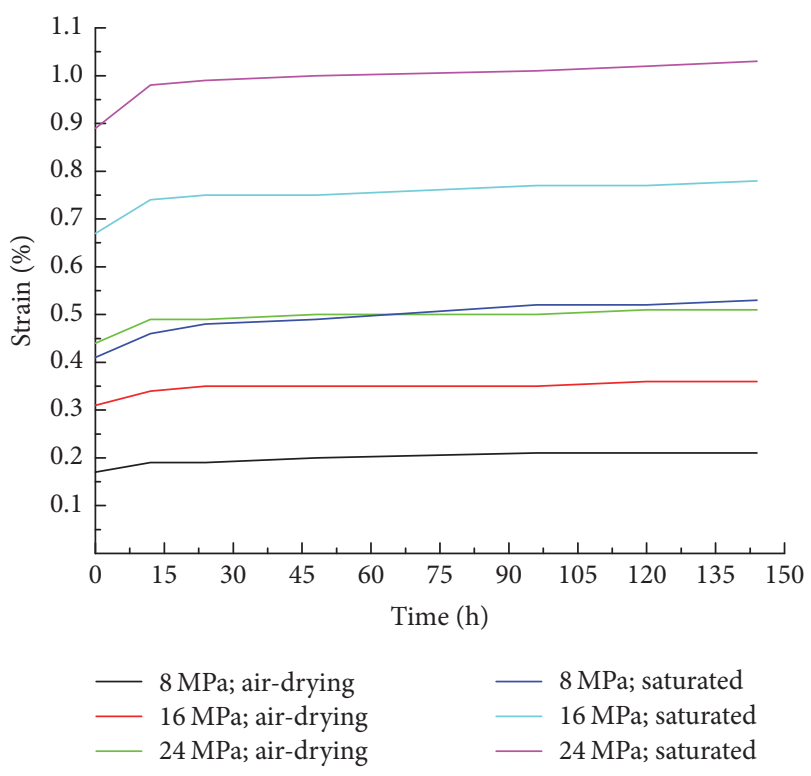

Figure 22: Time-strain curves of the typical red sandstone.

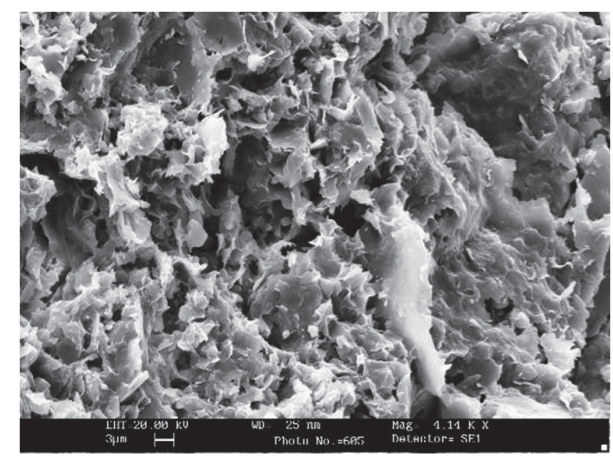

FIGURE 23: SEM picture of Tiyu West Road Station red clay sample, $\times 4140$ Honeycomb I/S with a small amount of needle-like C.

that of the saturated samples. Therefore, the influence of water content on the creep characteristics of red sandstone could not be ignored in the engineering design and construction of major projects in this area.

4.5. Mechanism of Water Content Influence on Red-Layers Properties Discussion. Studies have shown that the properties of rock or clay were often close to its mineral compositions, water content, and microstructures (Aziz et al. 2010; [8, 13, $14])$. Therefore, the XRD and FEM tests of red-layers specimens were conducted for further discussion about mechanism of water content influence on red-layers properties. For the simplicity consideration, only the part results of XRD and FEM tests were shown in Tables 4 and 5 and Figures 23-28, and the mineral compositions in Figures 23-26 were expressed as follows: C-chlorite, I/S-illite, and smectite mixed layer; $\mathrm{C} / \mathrm{S}$ - chlorite and smectite mixed layer.

The following two points were made based on typical redlayers samples, SEM micrographs, and XRD photos. 
TABLE 4: X-ray diffraction results of the remaining samples.

\begin{tabular}{|c|c|c|c|c|c|c|c|c|c|c|c|}
\hline \multirow[t]{2}{*}{ Number } & \multirow[t]{2}{*}{ Sampling site } & \multirow{2}{*}{$\begin{array}{l}\text { Sampling } \\
\text { depth }(\mathrm{m})\end{array}$} & \multirow[t]{2}{*}{ Lithology } & \multicolumn{6}{|c|}{ Clay mineral relative content (\%) } & \multicolumn{2}{|c|}{$\begin{array}{l}\text { Mixed layer } \\
\text { ratio (\% S) }\end{array}$} \\
\hline & & & & S & $\mathrm{I} / \mathrm{S}$ & I & Kao & $\mathrm{C}$ & $\mathrm{C} / \mathrm{S}$ & $\mathrm{I} / \mathrm{S}$ & $\mathrm{C} / \mathrm{S}$ \\
\hline KD01 & $\begin{array}{c}\text { Tiyu West Road } \\
\text { Station }\end{array}$ & 16 & $\begin{array}{l}\text { Moderate weathered } \\
\text { red clay }\end{array}$ & 54 & l & 46 & l & / & l & l & / \\
\hline KD02 & $\begin{array}{l}\text { Zhujiang New } \\
\text { Town Station }\end{array}$ & $17.2 \sim 17.8$ & Red clay & 64 & l & 36 & / & l & l & l & / \\
\hline KD03 & $\begin{array}{l}\text { Wushan Road } \\
\text { Station }\end{array}$ & 12 & $\begin{array}{l}\text { Moderate-strong } \\
\text { weathered red clay }\end{array}$ & 2 & 46 & 42 & 4 & 6 & l & 15 & / \\
\hline KD04 & $\begin{array}{l}\text { Zhujiang New } \\
\text { Town Station }\end{array}$ & $18.1 \sim 19.0$ & Sandstone & l & 47 & 44 & 3 & 6 & 1 & 15 & / \\
\hline KD05 & Kecun Station & 27.6 & Red sandstone & 3 & 75 & 20 & 1 & 1 & I & $40 / 25$ & / \\
\hline KD06 & Tianhe Station & 16 & Shield excavated soil & 1 & I & 56 & 38 & 6 & 1 & 1 & I \\
\hline
\end{tabular}

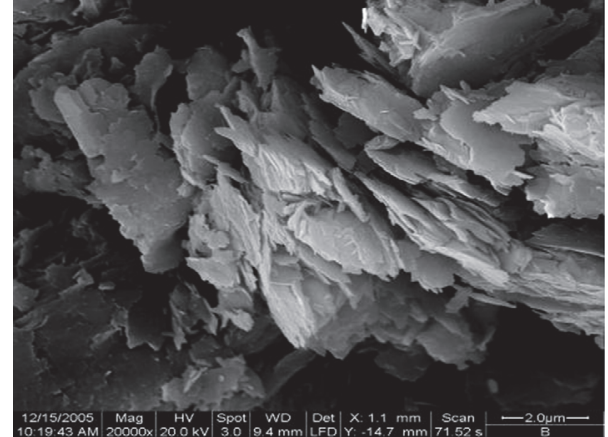

FIGURE 24: SEM picture of Zhujiang New Town Station sample, $\times 20000$ leaf shaped and laminated C.

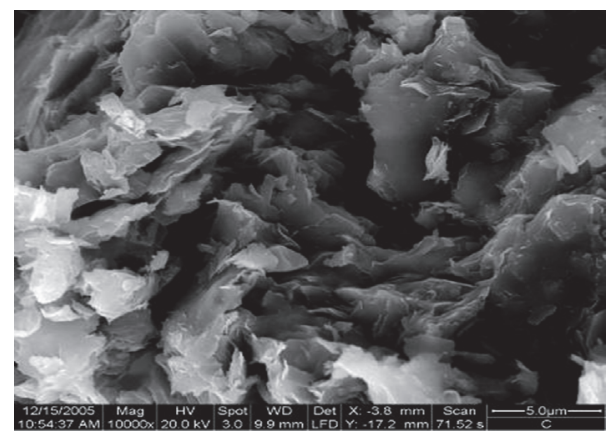

FIGURE 25: SEM picture of Wushan Road Station sample, a $\times 10000$ filament I/S.

(1) The microstructures of samples were relatively loose; the larger pores of the different samples were about $30-200 \mu \mathrm{m}$ between the particles, with the good connectivity. The samples contained numerous needle-like chlorite, flakeflocculent chlorite, honeycomb and flaky illite, and smectite mixed layer and chlorite and smectite mixed layer, with the authigenic polyhedral quartz and strip albite crystal existing in particles.

(2) Tiyu West Road Station sample mainly contained 54\% smectite and $46 \%$ illite. Zhujiang New Town Metro Station

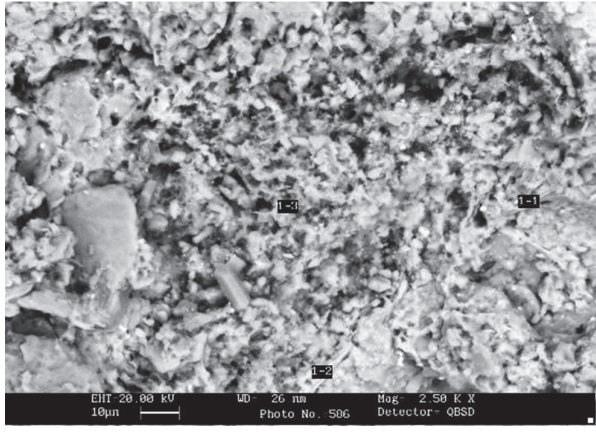

FIgURE 26: Energy spectrum picture of red clay sample in Tiyu West Road Station, a×2500 1-1 I/S; 1-2 I/S; 1-3 C/S.

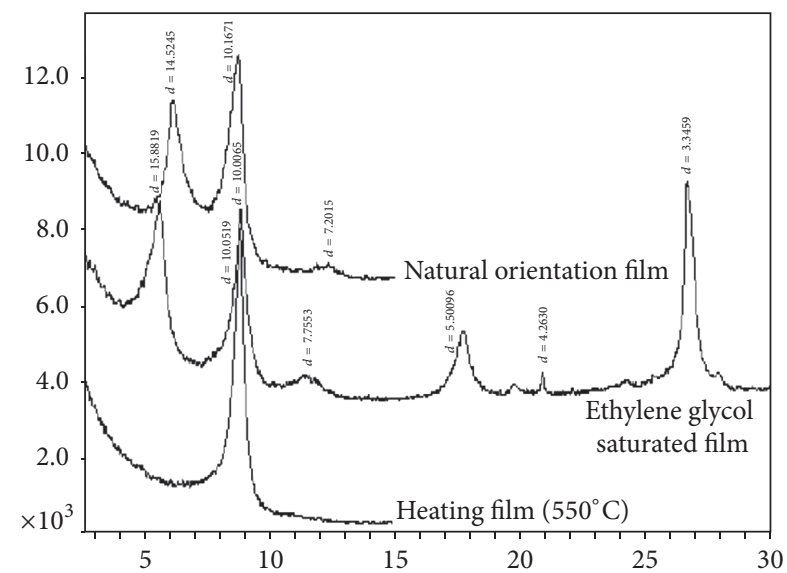

Figure 27: X-ray diffraction pattern of red clay in Tiyu West Road Station.

sample relative contents were $39.9 \%$ clay minerals, $45.7 \%$ quartz, $10.9 \%$ plagioclase, and $3.5 \%$ hematite.

Influence of water content on the red-layers specimens was a complex phenomenon; the water induced change in microstructures and mineral compositions yielded degradation of physical and mechanical parameters. Therefore, it was important to analyze the effects of water content 


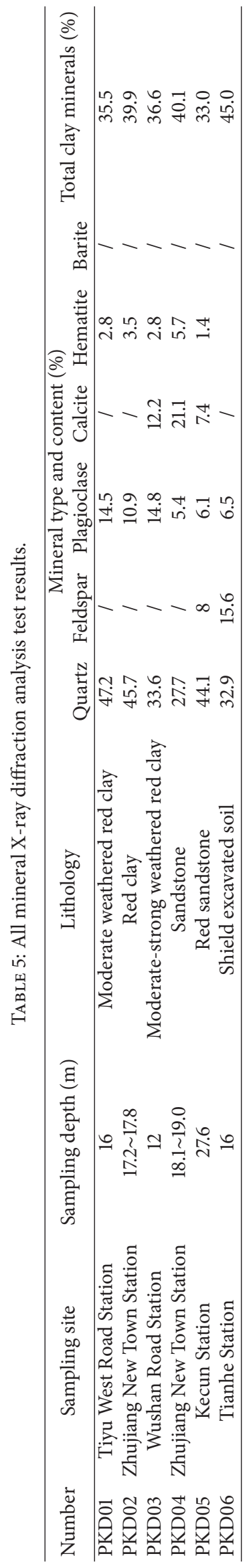




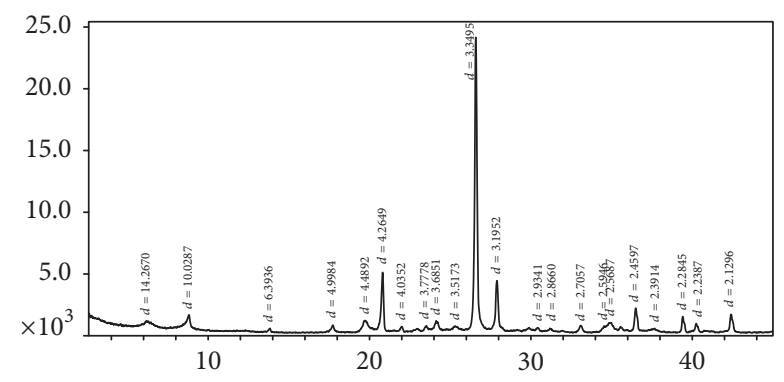

Figure 28: Total minerals from X-ray diffraction pattern of red clay samples in Zhujiang New Town Station.

on the degradation mechanism of the specimens, as those conditions considered during above-mentioned experiments.

(1) The typical red-layers samples had layered or honeycomb microstructures and easily water swelling or weakening minerals such as chlorite and smectite, and the pores had good connectivity between the particles which provided the water invasion tunnels.

(2) With the lower water content, the particles and layers made good contact with each other and the contact surfaces were flat and smooth and formed the good microstructures which induced the relative good physical and mechanical properties.

(3) During the process of water content increasing, the water infiltrated inside the specimens. The chemical reactions such as dissolution and corrosion occurred in the mineral particles, and the chemical migration and dissolution occurred at the cemented or contact surfaces between mineral particles, which could make the mineral compositions and microstructures change and the macro physical and mechanical degradation of the specimens.

(4) Since the red-layers specimens are comprised of many minerals and then could easily expand inside the water, during water invasion, the cracks would likely propagate by the stress concentrated at the crack endpoints [15]. It was favorable for the formation of infiltration channels and water molecules seepage within the specimens. The reactions between minerals and aqueous solution were accelerated, which increased the change in microstructures and promoted the extension and coalescence of cracks and microtunnels. These factors were the mechanism of water content effect on the red-layers properties like shear strength, swelling, creep, and so on.

\section{Conclusion}

The widely spread red-layer in the Southeast China is hard and integrity, which has favorable physical and mechanical properties in natural condition, but it will rapidly expand, disintegrate, and soften after water invasion, which brings a great challenge for those region engineering construction. To reveal the effects of water content on the physical and mechanical properties of the typical Southeast China redlayers, the different tests such as the direct shear test, UU triaxial test, swelling test, and creep test were executed; the following conclusions could be made based on the findings of this paper.

(1) The internal friction angle $\phi$ exponentially decreased with the increase of water content $w$; the fitting equation was shown as (1). The cohesion $c$ firstly increased and then decreased in accordance with the Gaussian function with the increase of water content $w$, the fitting function was shown as (2), and the inflection point occurred in the vicinity of $w=$ $21.938 \%$.

(2) The UU triaxial test results of the typical Zhujiang New Town Metro Station reconstituted red-layers further validated the trend of water content effect on cohesion.

(3) The red-layers specimens had strongly swelling potential; the expansion rate obviously decreased with the increase of water content but was not significant after water content beyond $23.5 \%$.

(4) The air-drying red sandstone samples had strongly an isotropic expansibility and disintegration; the average vertical swelling was larger than average transverse expansion. The water contents and time curves of the unconfined swelling test could provide reference for solving the technical problems related to the civil engineering construction in typical red-layers.

(5) The mechanism of water content effect on red-layers properties was water induced microstructures and mineral compositions change which caused the macro physical and mechanical characteristics degradation.

\section{Conflicts of Interest}

The authors declare that they have no conflicts of interest.

\section{Acknowledgments}

The support of the Fujian Province Natural Science Fund, Grant no. 2016J01743, and the support of the Sanming University Science Research Development Fund and Fujian Province Young Teacher Education Research Project, Grants nos. JAT160454 and B201603, are gratefully acknowledged.

\section{References}

[1] Q.-L. Cui, H.-N. Wu, S.-L. Shen, and Y.-S. Xu, "Geological difficulties and countermeasures for socket diaphragm walls in weathered granite in Shenzhen, China," Bulletin of Engineering Geology and the Environment, vol. 75, no. 1, pp. 263-273, 2016.

[2] Q.-L. Cui, H.-N. Wu, S.-L. Shen, Z.-Y. Yin, and S. Horpibulsuk, "Protection of neighbour buildings due to construction of shield tunnel in mixed ground with sand over weathered granite," Environmental Earth Sciences, vol. 75, no. 6, pp. 458-469, 2016.

[3] W. B. Shi, Y. L. Lian, and X. L. Tang, "Discussion on the relationship between shear strength and water content of Guiyang red clay," Subgrade Engineering, no. 4, pp. 80-85, 2011.

[4] Y. H. Wang, Q. X. Zhang, and P. C. Tian, "Effects of water content variation on the deformation and shear strength of laterite clay," Geotechnical Investigation \& Surveying, vol. 37, no. 7, pp. 10-13, 2009.

[5] Y. Xu, C. Y. Zhou, Z. Liu, D. L. Su, and Z. C. Du, "Model tests for failure mechanism of typical soft rock slopes of red beds under 
rainfall in South China," Chinese Journal of Rock Mechanics and Engineering, vol. 35, no. 3, pp. 549-557, 2016.

[6] J. X. Liu and Y. T. Liu, "Study on engineering characteristics and centrifugal test of red bed," Subgrade Engineering, no. 2, pp. 7880, 2010.

[7] J. Zhang, Q. Jiang, Y. Zhang, L. Dai, and H. Wu, “Nondestructive measurement of water content and moisture migration of unsaturated red clays in South China," Advances in Materials Science and Engineering, vol. 2015, Article ID 542538, 7 pages, 2015.

[8] H. F. Deng, M. L. Zhou, J. L. Li, X. S. Sun, and Y. L. Huang, "Creep degradation mechanism by water-rock interaction in the red-layer soft rock," Arabian Journal of Geosciences, vol. 9, no. 12, pp. 601-613, 2016.

[9] S.-K. Ma, M.-S. Huang, P. Hu, and C. Yang, "Soil-water characteristics and shear strength in constant water content triaxial tests on Yunnan red clay," Journal of Central South University, vol. 20, no. 5, pp. 1412-1419, 2013.

[10] D. X. Geng, J. Guo, H. M. Li, and C. Zhang, "Study on shear strength of unsaturated red clay with triaxial tests," Applied Mechanics and Materials, vol. 501-504, pp. 444-450, 2014.

[11] W. J. Hu, Y. Ding, Z. Y. Xia et al., "Experimental study on confined swelling characteristic of redbed mudstone in Chongqing," Journal of Disaster Prevention and Mitigation Engineering, vol. 35, no. 5, pp. 607-611, 2015.

[12] Q. T. Bi, G. P. Jiang, and S. Y. Ding, "Water content influence on the shearing strength of red clay," Earth and Environment, vol. 33, no. 3, pp. 144-147, 2005.

[13] Q. Jiang, J. Cui, X. Feng, and Y. Jiang, "Application of computerized tomographic scanning to the study of water-induced weakening of mudstone," Bulletin of Engineering Geology and the Environment, vol. 73, no. 4, pp. 1293-1301, 2014.

[14] W. X. Kang, H. C. Yu, L. L. Wang, and Z. Q. Huang, "Experimental study of influence of water on creep properties of silty mudstone under triaxial compression," Journal of Engineering Geology, vol. 21, no. 4, pp. 622-628, 2016.

[15] L. S. Tang, P. Zhang, and Y. Wang, "Propagation of the complex cracks in rocks II. Under water pressure and chemical damage," Acta Scientiarum Naturalium Universitatis Sunyatseni, vol. 42, no. 1, pp. 90-94, 2003. 

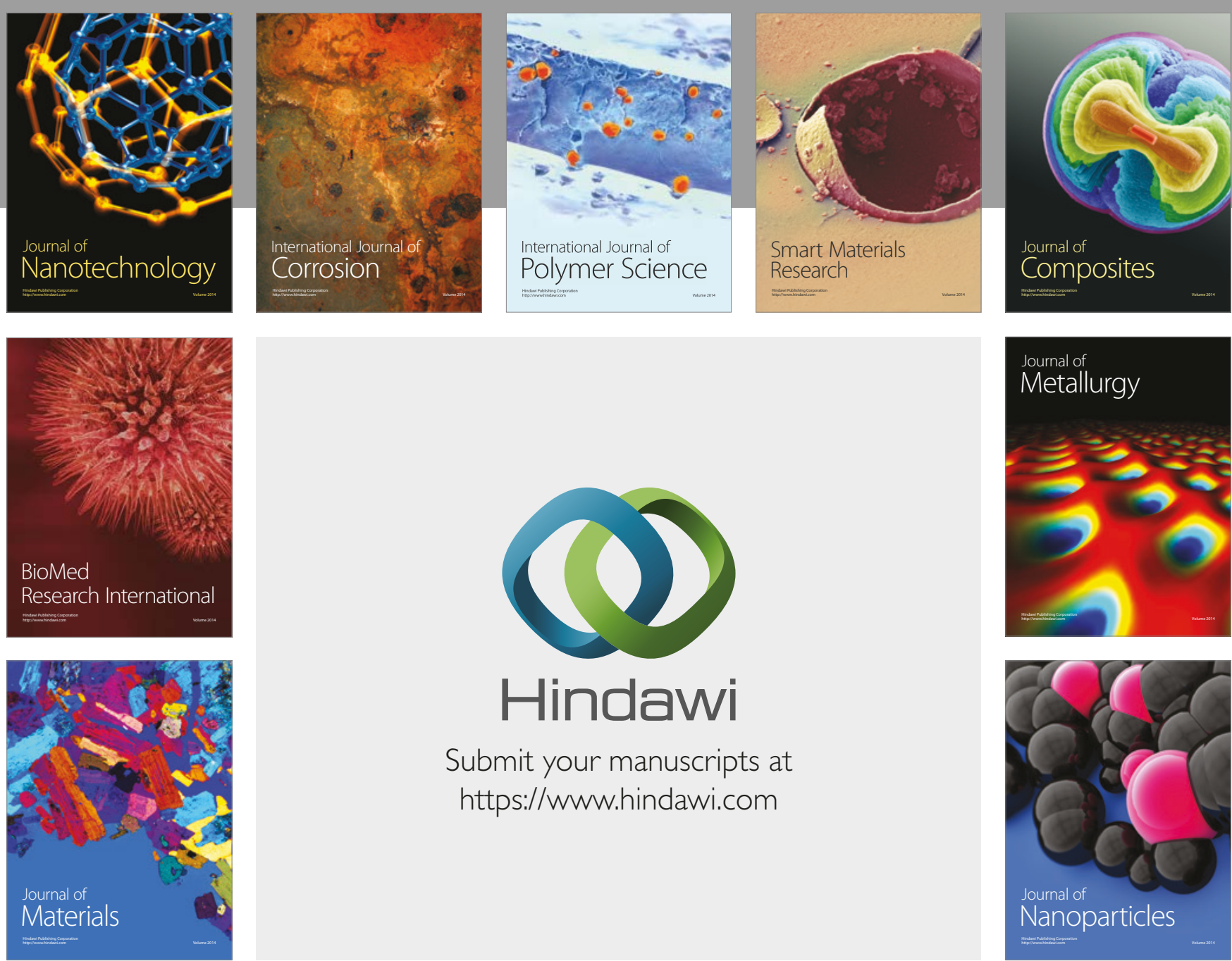

\section{Hindawi}

Submit your manuscripts at

https://www.hindawi.com
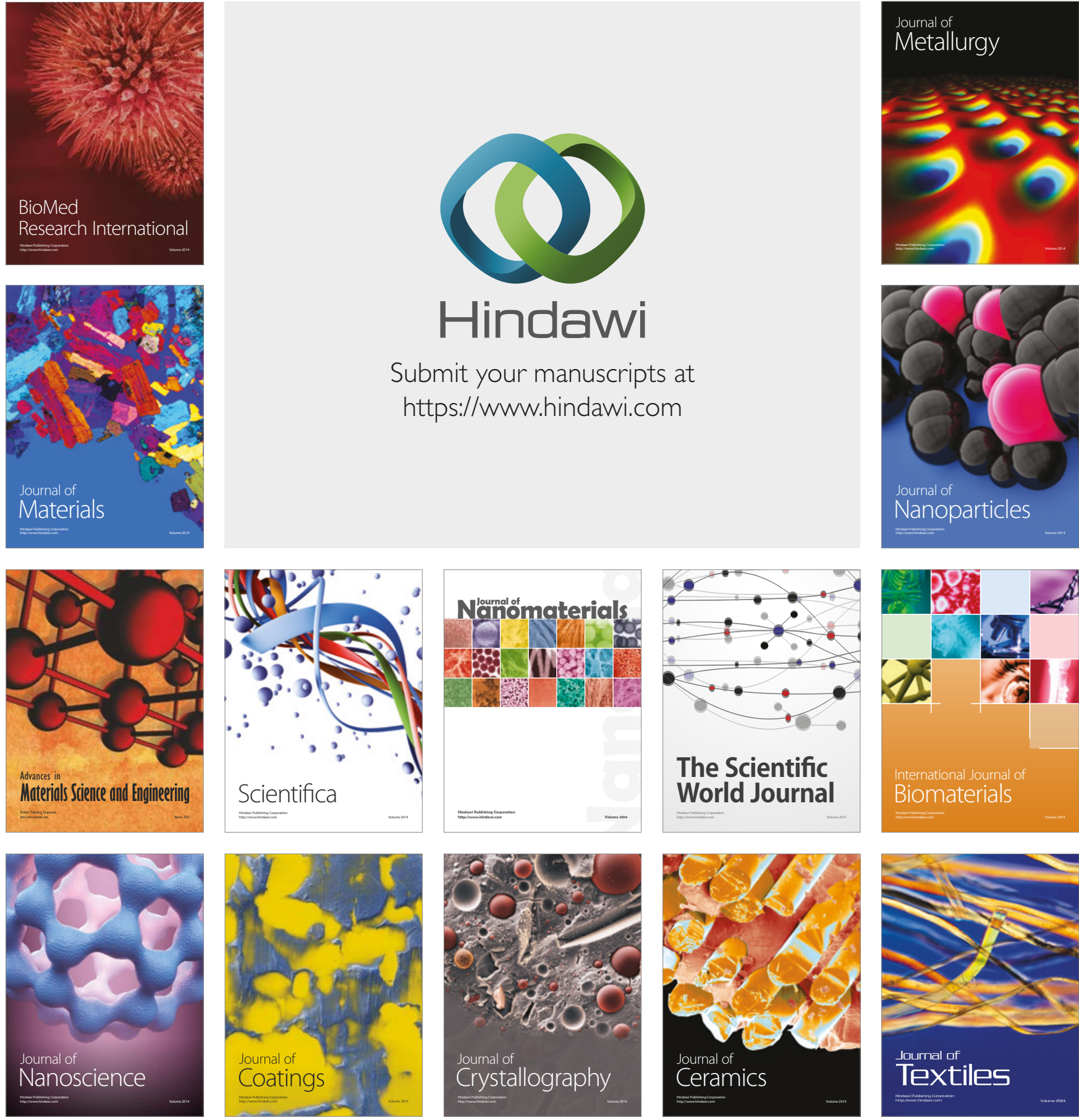

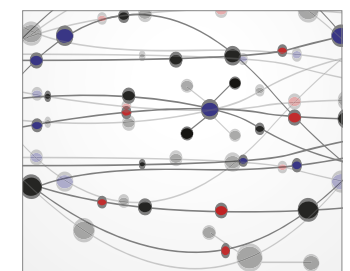

The Scientific World Journal
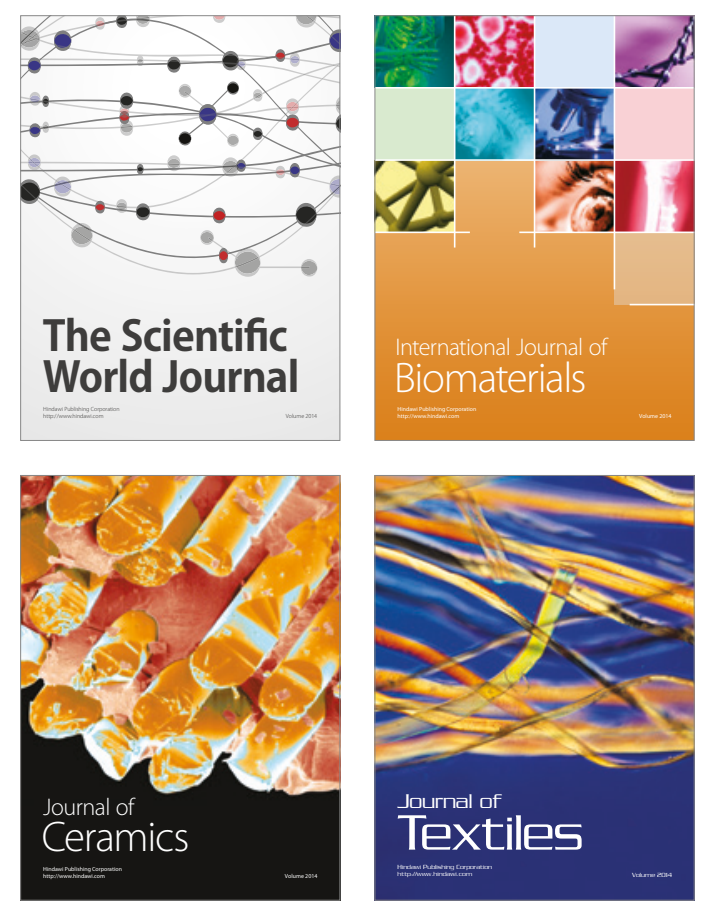